\title{
Studies on Production of Functional Noodles with Incorporation of Spinach Puree
}

\author{
P. D. Shere*, A. N. Devkatte and V. N. Pawar \\ MIT College of Food Technology, MIT Art, Design and Technology University, \\ Lonikalbhor, Pune, India \\ *Corresponding author
}

\section{A B S T R A C T}

\begin{tabular}{|l|}
\hline Ke y w or d s \\
$\begin{array}{l}\text { Spinach puree, } \\
\text { Noodles, Cooking } \\
\text { quality, Colour, } \\
\text { Sensory qualities }\end{array}$ \\
\hline Article Info \\
\hline $\begin{array}{l}\text { Accepted: } \\
\text { 17 May } 2018 \\
\text { Available Online: } \\
\text { 10 June } 2018\end{array}$ \\
\hline
\end{tabular}

Keywords

Spinach puree, Noodles, Cooking quality, Colour, Sensory qualitie

Aricle Info

Accepted:

Available Online:

June 2018

\section{Introduction}

Noodles are very thin form mostly made of wheat flour, water, egg and salt. Noodles have been increasingly important food commodity worldwide. 97.5 billion servings of instant noodles were eaten in 2016, by simple arithmetic as many as 270 millions servings are eaten every day (World Instant Noodle Association, 2016). The consumption level of noodles has become one of the fastest growing sectors in Asian countries, due to their ease of cooking and long shelf life. Traditional noodles are claimed to lack dietary fiber,
The objective of this study was to explore the possibility of adding spinach puree in preparation of vegetable noodles. The vegetable noodles were studied for its sensorial qualities, cooking qualities and proximate composition. The spinach puree was added at , 30, 40 and $50 \mathrm{gm}$ per $100 \mathrm{gm}$ of wheat flour. The results showed that spinach puree respect to colour, flavour and texture were greatly improved with addition of spinach puree. The cooking time was found to be decreased with increase in level of spinach puree in noodles. The cooking weight and water absorption were also found to be increased with increase in level of spinach puree. The studies on color estimation revealed green color of the product was slightly reduced during cooking of noodles, color loss composition results showed that with increase in level of spinach puree in noodle, there was progressive increase in moisture, fiber and ash content, fat and protein content increased non-significantly whereas carbohydrate content was decreased significantly as compared to control noodles. 
of bioactive compounds, However, noodles enriched with bioactive compounds of vegetable origin is still limited Rekha et al., (2013) and Deep et al., (2014). Worldwide, people's lifestyle is continuously changing and with respect to eating habits, it is changing in an unhealthy direction Caballero, (2007). Both developed and developing countries are experiencing a nutrition transition.

This phenomenon is characterized by a decrease in physical activity and a too low consumption of vegetables and grains. Eating habits are now characterized by an increase in the consumption of high energy-dense foods, i.e. foods with a high amount of calories per gram of food. This lifestyle is one of the factors for the development of diseases such as obesity, which is now acknowledged as a global epidemic. In turn, obesity has been linked to the development of other chronic diseases such as type II diabetes, hypertension, coronary heart disease and several types of cancer. When it comes to childhood obesity, concerns increase, since there are strong indications that it will persist into adulthood Wang et al., (2010).

One of the most effective strategies to fight this problem involves the combination of physical activity and the consumption of low energy-dense foods, such as vegetables, at an early age. A hurdle for implementing this strategy is the fact that children often dislike vegetables. Vegetables are known to have health benefits but are often non-appealing to children/adolescents due to their bitterness, undesired texture, and their low satiating capacity Zeinstra et al., (2010). One of the possible solutions to increase vegetable intake by children is to incorporate vegetables in a food matrix that they do like. Several studies have shown that noodles are very much appreciated by children, making it an ideal candidate for the development of vegetable- enriched foods. Spinach is one of the important vegetable rich in vitamins, minerals and antioxidants, Enriching noodles with ingredients, like spinach vegetables paste, represents challenges since the incorporation of fresh purees rather than dried powder as other researches used elsewhere will enhance the color intensity and distribution of pigments in the dough. Thus improving the quality of noodles. This also avoids drying of vegetable purees prior to their addition to the flour. The major purpose of this research is to develop a functional herbal noodles with incorporation of spinach puree in preparation of instant noodles.

\section{Materials and Methods}

\section{Preparation of instant noodles}

\section{Preparation of spinach puree}

Fresh spinach leaves were procured from local market. Leaves were washed, sorted, stalks were removed and leaves were cut into pieces, steam cooked and ground in grinder. The mass was passed through muslin cloth to get the homogenous spinach puree.

\section{Noodle preparation}

Noodles were prepared according to a method described by Collado and Corke (1996) with some modifications. The noodles were prepared in a automatic laboratory Kent noodle maker. Dry ingredients were first mixed for about 5 minutes, followed by addition of whole egg, oil, spinach puree and water to form a crumbly mass and then extruded through a die with 12 outlets of 0.8 $\mathrm{mm}$ in diameter. The noodles were cut and cooked in steam for 5 minutes and dried at $50^{\circ} \mathrm{C}$ for 5 hours and packed in polyethylene pouches. The noodles produced from different blends of spinach and carrot with wheat flour are shown in table 1 . 


\section{Chemical analysis}

All the chemicals used in the present research work were of analytical grade. The proximate composition (Moisture, crude fat, crude protein, total ash and fiber) were analyzed using AOAC (2000). The total carbohydrates were determined by difference method.

\section{Sensory evaluation}

All dried noodles samples were prepared for sensory evaluation by cooking in soup solution before testing. The cooking was carried for optimum cooking time and served the hot for the panel members to evaluate for its colour, flavour texture and overall acceptability using 10 semi trained panel members with 9- point hedonic rating where $9=$ like extremely and $1=$ dislike extremely.

\section{Cooking characteristics}

\section{Optimum cooking time}

To determine optimum cooking time, $250 \mathrm{gm}$ of noodles were dispersed in $250 \mathrm{ml}$ boiling water. For every 30 seconds, a piece of noodle was held between a plastic paper and pressed gently until the white color of noodle at central portion of strand disappears. Optimum cooking time was achieved when the centre of noodles become transparent.

\section{Cooking loss}

Cooking loss was determined by measuring the amount of solid substance lost to cooking water. A $10 \mathrm{gm}$ sample of noodles was placed into $300 \mathrm{ml}$ boiling distilled water in a $500 \mathrm{ml}$ beaker. Cooking water was collected in an aluminum dish and placed in oven at $105{ }^{0} \mathrm{C}$ and evaporated to dryness.

The residue was weighed and reported as a percentage of starting material.
Dried residue in cooking water Cooking Loss $(\%)=$

Noodle weight before cooking

\section{Water absorption}

The water absorption was determined by the ratio of the weight of cooked noodles to the weight of noodles before cooking as described by AACC method AACC (2005).

Weight of cooked noodles Weight of raw noodles

Water absorption $(\%)=$-------- x 100

Weight of raw noodles

\section{Swelling index}

The swelling index of cooked noodles was determined according to the procedure described by Cleary and Brennan (2006). The Swelling index was expressed as weight of cooked noodle,

Weight of cooked noodles Weight of noodles after drying Swelling Index =

Weight of noodles after drying

\section{Colour measurement}

The colour values of cooked and uncooked noodles were measured using Hunter lab colour measurement system using method of Jyotsna et al., (2004). (Colour measuring lab scan XE system, USA). A standard white tile of barium sulphate (100\% reflectance) was used as a perfect white surface for calibration of instrument with the illuminant.

Noodles samples were placed in the sample holder and reflectance was auto recorded for the wave length from $360-800 \mathrm{~nm}$. The values were recorded in terms of lightness $\mathrm{L}$ (Lightness: $0=$ black, $100=$ white) and colour (+a: red; -a: green; +b: yellow and -b: blue). 


\section{Statistical analysis}

The data obtained from the laboratory experiment was analyzed using completely randomized design and appropriately interpreted as per the methods described in" Statistical methods for agricultural workers" by Panse and sukhatme (1985). Appropriate standard error (S.E) and critical differences (C.D.) at $5 \%$ level were worked out as and when necessary and used for data interpretation.

\section{Results and Discussion}

The proximate composition of refined wheat flour, spinach puree and egg is shown in table.1.

The wheat flour contained $10.86 \%$ moisture, $1.56 \%$ crude fat, $11.6 \%$ protein, $1.67 \%$ fibre and $0.59 \%$ ash. Spinach was rich in moisture $(90.70 \%)$ ash $(1.40 \%)$, fibre $(1.67 \%)$ and fat $(0.28 \%)$. Egg was also rich in fat, protein and ash. The results are in agreement with several workers.

\section{Sensory evaluation of spinach puree added noodles}

Results pertaining to the sensory qualities of noodles added with spinach puree are presented in table.2.

Spinach puree was added in refined wheat flour at 10,20,30,40 and $50 \mathrm{gm}$ per $100 \mathrm{gm}$ flour and noodles were prepared and sensory evaluation was carried out. The significance differences were found in various parameters. The colour of the product greatly improved with the addition of spinach puree. The colour is the first quality parameter customer identification in food. It is the most important attribute used by customer to evaluate the quality of the product and it is the only test carried out without touching to the product.
The maximum score was allotted to the sample $\mathrm{Sp} 30$ and $\mathrm{Sp} 40$ as compared to control. Flavour, texture and overall acceptability were also significantly improved with addition spinach puree in noodles. Overall acceptability was greatly improved in Sp 30 and Sp 40 samples. However, the results pertaining to taste were not encouraging as the spinach imparts its vegetable taste to the product therefore, taste parameter obtained fewer score. The similar results with respect to colour were obtained Rekha et al., (2013). Similar results of increasing parameters with respect to appearance were reported by Keyimu (2013) with addition of sea weed puree in noodles up to 3\% level. Yadav et al., (2014) also reported that the spinach incorporated pasta was most acceptable than other pastas.

\section{Cooking qualities}

Cooking qualities affected by addition of spinach puree are presented in table 3 .

Cooking time refers to the time in minutes to gelatinize the starch marked by disappearance of central white core in the noodles strand De pilli et al., (2013). The results indicated that there were significant differences in time required to cook the control noodles and spinach noodles. Addition of spinach reduced the cooking time progressively from 6.24 (control) to 5.15 minutes (50gm spinach noodles). This might be due to dilution of gluten in dough. Gluten is primarily responsible for the development of starch/protein complex; which in term determines the noodles structure and cooking properties. The dilution of these constituents by addition of spinach puree might be reducing the cooking time Rekha et al., (2013). The results are in agreement with those described by Petitot et al., (2010) and Kuchtowa et al., (2016) in supplementation of wheat flour in pasta with faba bean flour and 
pumpkin powder. Reduction in cooking time was also observed by Padalino et al., (2017) in fortification of tomato peel flour in pasta.

\section{Cooking loss}

Cooking loss is amount of solids that dissolve in water during cooking and may be an indicator of noodles structure integrity during cooking Li et al., (2015). Cooking loss is commonly used as predictor of overall noodle cooking performance Tudorica et al., (2002).

Type of ingredients added directly affect the loss of soluble solids during cooking and has been reported that a compact texture of noodles often results in less cooking loss than the loose textured noodle Krishnan et al., (2012). From the results it can be clearly seen that cooking loss was maximum $(14.33 \%)$ in control. There was a progressive reduction in cooking loss with increasing level of spinach puree in formulation. This could be due to better binding of starch granules with added vegetable puree in gluten matrix Rekha et al., (2013) also reported decrease in gruel loss for vegetable paste in incorporated pasta.

\section{Water absorption}

Water absorption is indication of quantity of water absorbed by the noodles during cooking, an important characteristics in deciding the cooking quality Li et al., (2015). Results indicated that, there was slight increase in water absorption and consequently in cooking weight of noodles.

The water absorption for control was minimum and with increase in spinach puree water absorption was progressively increased from 150.27 (control) to 162.6 ( $\mathrm{Sp} \mathrm{50)}$ ). The addition of vegetable puree enhances the interaction between starch granules and protein matrix resulting in better quality noodles. Since, vegetables have greater water holding capacity therefore spinach puree added noodle samples had more water absorption as compared to control. Vegetable noodles had higher fiber content than control noodles, which resulted in higher water absorption due to strong water binding ability of fibers. Chen et al., (1998). The present results are in accordance with the results of Rekha et al., (2013).

\section{Swelling index}

Concerning swelling index the noodles samples with spinach puree recorded slightly lower values as compared with control samples. The results can be interpreted in terms of competition between fiber and starch for water absorption means starch components might have absorbed less water at optimum cooking time giving rise to lower swelling indices. Therefore increasing the amount of fiber thus generally resulted in lower swelling of starch and consequently lower swelling index. Padalino et al., (2017) also reported lower swelling index in spaghetti incorporated with tomato peel flower.

\section{Colour measurement}

Colour is a major factor for assessing the visual quality and market value of a product. Colour values were measured for cooked and uncooked noodles and control sample with $100 \%$ flour was used to compare the colour.

The table 4 represents the colour characteristics of cooked and uncooked noodles. The control sample had the highest L value both in cooked and uncooked samples. During cooking lightness was slightly increased. In general lightness decreased continuously and progressively with increase in spinach level in the noodle. It was also observed that there was some loss of colour during cooking and therefore corresponding increase in $\mathrm{L}$ value. 
Fig.1 Flow sheet for production of spinach puree

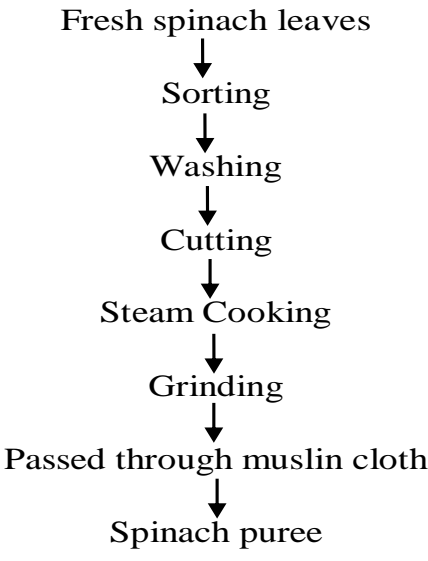

Plate.1 Spinach puree

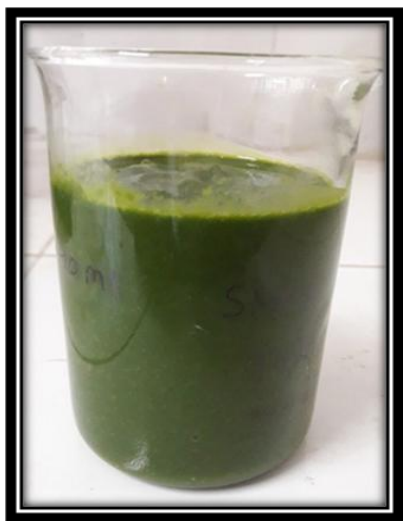

Plate.2 Spinach Puree Added Noodles

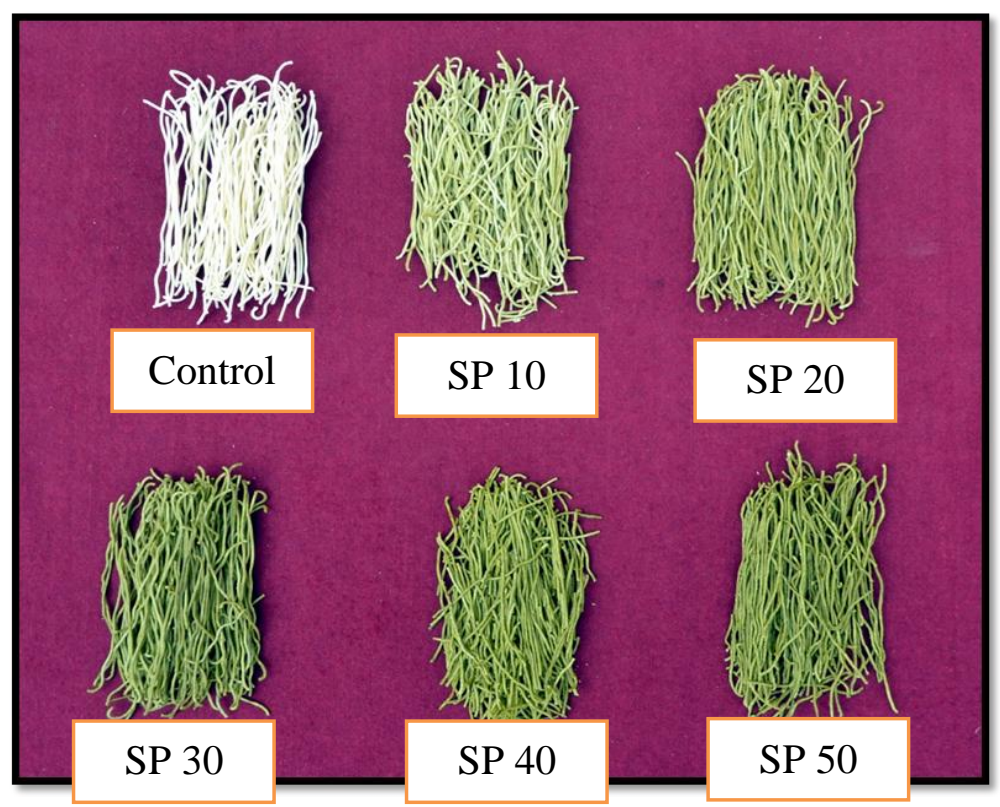

1623 
Table.1 Formulation of instant noodles with spinach puree and carrot puree

\begin{tabular}{|c|c|c|c|c|c|c|}
\hline Ingredients & $\mathrm{Sp}_{0}$ & $\mathbf{S p}_{10}$ & $\mathrm{Sp}_{20}$ & $\mathrm{Sp}_{30}$ & $\mathrm{Sp}_{40}$ & $\mathrm{Sp}_{50}$ \\
\hline Wheat flour(g) & 100 & 100 & 100 & 100 & 100 & 100 \\
\hline Spinach puree (g) & - & 10 & 20 & 30 & 40 & 50 \\
\hline Whole egg (g) & 8 & 8 & 8 & 8 & 8 & 8 \\
\hline Water (g) & 30 & 30 & 30 & 30 & 25 & 20 \\
\hline
\end{tabular}

$\mathrm{SP}_{0}=$ Control $100 \%$ wheat flour noodles

$\mathrm{SP}_{10}=10 \mathrm{~g}$ spinach puree in $100 \mathrm{~g}$ flour

$\mathrm{SP}_{20}=20 \mathrm{~g}$ spinach puree in $100 \mathrm{~g}$ flour

$\mathrm{SP}_{30}=30 \mathrm{~g}$ spinach puree in $100 \mathrm{~g}$ flour

$\mathrm{SP}_{40}=40 \mathrm{~g}$ spinach puree in $100 \mathrm{~g}$ flour

$\mathrm{SP}_{50}=50 \mathrm{~g}$ spinach puree in $100 \mathrm{~g}$ flour

Table.2 Chemical composition of raw material

\begin{tabular}{|c|c|c|c|c|c|c|}
\hline Sample & $\begin{array}{c}\text { Moisture } \\
(\%)\end{array}$ & Fat $(\%)$ & $\begin{array}{l}\text { Protein } \\
(\%)\end{array}$ & $\begin{array}{c}\text { Carbohydrate } \\
(\%)\end{array}$ & $\begin{array}{l}\text { Fibre } \\
(\%)\end{array}$ & Ash (\%) \\
\hline $\begin{array}{l}\text { Refined wheat } \\
\text { flour }\end{array}$ & 10.86 & 1.56 & 11.6 & 71.38 & 1.67 & 0.59 \\
\hline Spinach puree & 90.70 & 0.28 & 1.8 & 4.15 & 1.67 & 1.40 \\
\hline Egg & 73.30 & 11.20 & 12.5 & 0.20 & Trace & 2.8 \\
\hline $\mathrm{SE} \pm$ & 0.5151 & 0.1056 & 0.5172 & 0.3865 & 0.1155 & 0.1007 \\
\hline CD at $5 \%$ & 1.6798 & 0.3444 & 1.6867 & 1.2604 & 0.3997 & 0.3284 \\
\hline
\end{tabular}

Table.3 Sensory evaluation of spinach puree noodles

\begin{tabular}{|c|c|c|c|c|c|}
\hline Sample & Colour & Flavor & Taste & Texture & Overall acceptability \\
\hline SP $_{0}$ & 6.5 & 7.5 & 7.50 & 7.5 & 7.5 \\
\hline SP $_{10}$ & 7.50 & 7.25 & 7.50 & 7.75 & 7.75 \\
\hline SP $_{20}$ & 8.0 & 7.50 & 7.50 & 8.00 & 8.25 \\
\hline SP $_{30}$ & 9.0 & 8.0 & 7.00 & 8.50 & 8.50 \\
\hline SP $_{40}$ & 9.0 & 8.0 & 7.00 & 8.75 & 8.75 \\
\hline SP $_{50}$ & 8.50 & 8.0 & 6.5 & 8.25 & 8.0 \\
\hline SE \pm & 0.1196 & 0.1394 & 0.1146 & 0.1222 & 0.1644 \\
\hline CD at 5\% & 0.3686 & 0.4296 & 0.3531 & 0.3766 & 0.5066 \\
\hline
\end{tabular}

$\mathrm{SP}_{0=}$ Control $100 \%$ wheat flour noodles $\mathrm{SP}_{10}=10 \mathrm{~g}$ spinach puree in $100 \mathrm{~g}$ flour $\mathrm{SP}_{20}=20 \mathrm{~g}$ spinach puree in $100 \mathrm{~g}$ flour $\mathrm{SP}_{30}=30 \mathrm{~g}$ spinach puree in $100 \mathrm{~g}$ flour $\mathrm{SP}_{40}=40 \mathrm{~g}$ spinach puree in $100 \mathrm{~g}$ flour $\mathrm{SP}_{50}=50 \mathrm{~g}$ spinach puree in $100 \mathrm{~g}$ flour 
Table.4 Cooking qualities of spinach puree added noodles

\begin{tabular}{|c|c|c|c|c|c|}
\hline Sample & Cooking time (min) & $\begin{array}{c}\text { Cooking weight } \\
(\%)\end{array}$ & Cooking loss (\%) & Swelling index (ml/g) & $\begin{array}{c}\text { Water absorption } \\
(\%)\end{array}$ \\
\hline Control & 6.24 & 250.31 & 14.33 & 1.85 & 150.27 \\
\hline SP $_{10}$ & 5.45 & 252.29 & 8.5 & 1.82 & 152.2 \\
\hline SP $_{20}$ & 5.25 & 254.45 & 7.65 & 1.82 & 154.4 \\
\hline PP $_{30}$ & 5.20 & 255.65 & 7.60 & 1.84 & 165.6 \\
\hline SP $_{40}$ & 5.18 & 260.75 & 7.40 & 1.89 & 162.6 \\
\hline SP $_{50}$ & 5.15 & 262.26 & 6.8 & 1.91 & 1.2085 \\
\hline SE \pm & 0.1426 & 1.9391 & 0.3278 & 0.1058 & 3.7241 \\
\hline CD at 5\% & 0.4394 & 5.9755 & 1.0101 & 0.3260 & \\
\hline
\end{tabular}

$\mathrm{SP}_{0=}$ Control $100 \%$ wheat flour noodles

$\mathrm{SP}_{10}=10 \mathrm{~g}$ spinach puree in $100 \mathrm{~g}$ flour

$\mathrm{SP}_{20}=20 \mathrm{~g}$ spinach puree in $100 \mathrm{~g}$ flour

$\mathrm{SP}_{30}=30 \mathrm{~g}$ spinach puree in $100 \mathrm{~g}$ flour

$\mathrm{SP}_{40}=40 \mathrm{~g}$ spinach puree in $100 \mathrm{~g}$ flour

$\mathrm{SP}_{50}=50 \mathrm{~g}$ spinach puree in $100 \mathrm{~g}$ flour

Table.5 Color values of raw and cooked spinach noodles

\begin{tabular}{|c|c|c|c|c|c|c|c|}
\hline \multirow{2}{*}{ Sample } & \multicolumn{2}{|c|}{ L } & \multicolumn{2}{|c|}{ a } & \multicolumn{2}{c|}{ b } \\
\hline Control & Raw & Cooked & Raw & Cooked & Raw & Cooked \\
\hline $\mathrm{Sp}_{10}$ & 69.29 & 69.44 & 2.43 & 0.87 & 24.63 & 13.58 \\
\hline $\mathrm{Sp}_{20}$ & 51.49 & 55.21 & -0.35 & -1.76 & 29.57 & 20.83 \\
\hline $\mathrm{Sp}_{30}$ & 43.73 & 50.37 & -.95 & -1.78 & 27.39 & 19.03 \\
\hline $\mathrm{Sp}_{40}$ & 35.30 & 49.62 & -1.00 & -1.86 & 26.34 & 21.42 \\
\hline $\mathrm{Sp}$ & 37.52 & 46.11 & -1.36 & -1.98 & 26.63 & 24.79 \\
\hline
\end{tabular}

$\mathrm{SP}_{0}=$ Control $100 \%$ wheat flour noodles; $\mathrm{SP}_{10}=10 \mathrm{~g}$ spinach puree in $100 \mathrm{~g}$ flour

$\mathrm{SP}_{20}=20 \mathrm{~g}$ spinach puree in $100 \mathrm{~g}$ flour; $\mathrm{SP}_{30}=30 \mathrm{~g}$ spinach puree in $100 \mathrm{~g}$ flour

$\mathrm{SP}_{40}=40 \mathrm{~g}$ spinach puree in $100 \mathrm{~g}$ flour; $\mathrm{SP}_{50}=50 \mathrm{~g}$ spinach puree in $100 \mathrm{~g}$ flour

Table.6 Proximate composition of spinach puree noodles

\begin{tabular}{|c|c|c|c|c|c|c|}
\hline Sample & Moisture (\%) & Fat (\%) & Protein (\%) & $\begin{array}{c}\text { Carbohydrate } \\
(\%)\end{array}$ & Fiber (\%) & Ash (\%) \\
\hline SP $_{0}$ & 6.83 & 4.30 & 13.85 & 69.93 & 1.85 & 1.57 \\
\hline SP $_{10}$ & 8.50 & 4.28 & 13.65 & 67.62 & 3.10 & 2.85 \\
\hline SP $_{20}$ & 8.70 & 4.26 & 13.55 & 67.08 & 3.20 & 3.21 \\
\hline SP $_{30}$ & 8.75 & 4.27 & 13.40 & 66.86 & 3.40 & 3.32 \\
\hline SP $_{40}$ & 8.98 & 4.26 & 13.20 & 66.51 & 3.60 & 3.45 \\
\hline $\mathrm{SP}_{50}$ & 9.50 & 4.25 & 13.05 & 65.80 & 3.80 & 3.60 \\
\hline SE \pm & 0.4255 & 0.237 & 0.5424 & 0.7781 & 0.2422 & 0.2739 \\
\hline CD at 5\% & 1.3407 & NS & NS & 2.3978 & 0.7464 & 0.8444 \\
\hline
\end{tabular}

$\mathrm{SP}_{0=}$ Control $100 \%$ wheat flour noodles; $\mathrm{SP}_{10}=10 \mathrm{~g}$ spinach puree in $100 \mathrm{~g}$ flour

$\mathrm{SP}_{20}=20 \mathrm{~g}$ spinach puree in $100 \mathrm{~g}$ flour; $\mathrm{SP}_{30}=30 \mathrm{~g}$ spinach puree in $100 \mathrm{~g}$ flour

$\mathrm{SP}_{40}=40 \mathrm{~g}$ spinach puree in $100 \mathrm{~g}$ flour; $\mathrm{SP}_{50}=50 \mathrm{~g}$ spinach puree in $100 \mathrm{~g}$ flour 
Uncooked and cooked spinach pasta had green colour as seen from negative " $a$ " that indicates green shade. It also had some yellowness as indicated by its " $b$ " value. These values indicated that the noodles had green natural colour of spinach used. The colour of cooked sample was slightly less green than corresponding uncooked sample. Leaching of colour during cooking was almost negligible and all noodles had attractive green colour after cooking also. The results of present investigation were in accordance with the finding of Rekha et al., (2013).

\section{Chemical Characteristics}

Chemical characteristics of spinach noodle are presented in table 5.

The moisture content of different noodles significantly affected with addition of spinach puree. Addition of spinach puree increased moisture content progressively and it was significantly different $(\mathrm{P}<0.05)$ to the control. Moisture content of control noodle was lower as compared to other noodles. There was a progressive increase in moisture content of noodles with increase in proportion of spinach puree in wheat flour from $6.83 \%$ (Control) to 9.50 (Sp 50). The higher moisture content in spinach noodles may be due to higher water holding capacity of fibers in spinach puree during dough formation. Spinach puree was comprised of small fine particles of cellulosic matters and hence when it was mixed with wheat flour to form dough it resulted in unhomogenous dough and which caused in increased moisture adsorption Lahaye (2001). The increase in moisture content with addition of seaweed puree in noodles was also reported by Eko Nurcahya (2011).

The results pertaining to fat and protein content were found to be non-significant with that of control. The fat and protein content was in the range of 4.30 (control) to 4.25 (Sp50) and protein content was 13.85 (control) to 13.05 (Sp50). In general fat and protein content slightly decreased with increase in level of spinach puree in noodles. This might be due to lower percentage of fat and protein in spinach puree.

There was a significant difference in carbohydrate content of noodles and control. In general carbohydrate content decreased progressively with addition of spinach puree in noodles. Fiber and ash content was found to be increased significantly in spinach noodles than control noodles.

There was a progressive increase in both the constituent with increase in level of spinach puree in noodle formulation. Fiber and ash content were almost double in Sp40 and Sp50 as compared to control noodles. Increase in fiber and ash content was also noted by Eko Nurcahya (2011) in substitution of seaweed puree in noodles.

The spinach puree can be added up to $40 \mathrm{gm}$ per $100 \mathrm{gm}$ of wheat flour. The sensorial parameters were improved with addition of spinach puree. The cooking time and cooking loss was reduced with increase in level of spinach puree in formulation. Whereas cooking weight, swelling index and water absorption was increased with increase in level of spinach puree in the noodle formulation.

The green colour in cooked and uncooked sample was progressively increased with increase in level of spinach. Moisture was significantly increased with increase in level of spinach puree. Fiber percent and ash content was also progressively increased with increase in level of spinach puree in formulation. The carbohydrate content was significantly decreased as compared to control noodles. 


\section{References}

AACC 2005. Approved methods of the American Association of cereal chemists. St paul Minnesota.

AOAC 2000. Association of Official Analytical Chemists. Official Methods of Analysis of AOAC International. 17 Edition. Vol. 2, Washington. DC, USA.

Betoret, E., Betoret, N., Vidol, D. and Fito, P., 2011. Functional foods development: Trends in Food Science and Technology, 22(9):498-508.

Caballero, B. 2007. The global epidemic of obesity: An overview. Epidemiologic Reviews, 9(1):1-5.

Chen, H., Rubenthal, L., Leung, H.K. and Baranwski, J.D 1998. Chemical physical and baking properties of apple fiber compared with oat bran. Cereal chemistry 65(3):242-247

Cleary, L. and Brennan, C. 2006. The influence of $(1 \rightarrow 3)(1 \rightarrow 4) \beta$ glucan rich fraction from barley on the physicochemical properties and in vitro reducing sugars release of duram wheat pasta. International Journal of Food Science and Technology 41:910-918.

Collado, L.S and Corke, H 1996.Use of wheat -sweet potato composite in yellow alkaline and white salted noodles. Cereal chemistry 73(4):439-444.

De Pilli, T., Derossi, A., Severini, C. 2013. Cooking Quality Characteristics of Spaghetti based on Soft Wheat Flour Enriched with Oat Flour. International Journal of Food Science and Technology. 48(11): 2348-2355.

Deep N.Y., M, Sharma, Chilkara, N., Anand, T. and Bansal, S. 2014. Quality characteristics of vegetable blended wheat-pearl millet composite pasta. Agricultural Research, 3:263-270.

Eko Nurcahya Dewi 2011. Quality evaluation of dried noodles with seaweed puree substitution. Journal of coastal development 14(2): 151-158

Jyotsna, R, Prabhashankar, P, Indrani, D and Venkateswara Rao, G. 2004. Effect of additives on the quality and microsture of vermicelli made from triticum aestivum. European Food Research Technology, 218:557-562.

Keyimu Xiren Guli 2013. The effects of using seaweed on the quality of asian noodles. Journal of Food Process Technology 4(3): 1000216-1000219.

Krishnan, J.G., Menon, R., Padmaja, G., Sanjeev, M.S. and Moorthy, S.N. 2012. Evaluation of nutritional and physicochemical characteristics of dietary fiber enriched sweet potato pasta. European Food Research and Technology 234(3): 467-476.

Kushtova,V., Kohajdova, Z., Karovicova, J., and Mesterova, E. 2016. Use of pumpkin fiber for the preparation of pasta. Chemicke listy 110(11): 808-811.

Lahaye, M. 2001. Developments on gelling algal galactans, their structure and physic-chemistry. Journal of Applied Physics (13):173-184.

Li. P., Lu, W., Hseih, Ch. Li. T., and Huang D. 2015. Rheological properties of dough and quality of slated noodles supplemented with djulis flour. Journal of agricultural science 7(6):84-92.

Padelino, Lucia, Conte Amalia, Lecce Lucia, Likyova, Desislava, Sicari, Vincenzo, Pellicanò, Teresa Maria, Poiana, Marco and DelNobile Matteo Alessandro 2017. Functional pasta with tomato byproducts as a source of antioxidant compounds and dietary fibre. Czech Journal Food Science 35(1): 48-56.

Panse U.G. and Sukhatme, P.V. 1985. Statistical Methods for Agricultural Workers. Indian Council of Agricultural Reaserach Publication, New Delhi.

Petitot, M., Boyer, L., Minier, C and Micard, V. 2010. Fortification of pasta with split 
pea and faba bean flours: pasta processing and quality evaluation. Food Research International. 43(2): 634-641.

Rakesh, N., Fellows, C.M., Sissons, M. 2015. Evaluation of the technological and sensory properties of durum wheat spaghetti enriched with different dietary fibers. Journal of the science of the food and agriculture 95(1):2-11.

Rekha M.N., Chauhan A.S., Prabhashankar, P, Ramteke, R.S. and Venkateswara Rao G 2013.Influence of vegetable paste on quality attributes of pastas made from bread wheat (T.Aestivum) Cyta. Journal of Food 11:142-149

Tudorica, C.M., Kuri, V. and Brenan, S. 2002. Nutritional and physiological characteristics of dietary fiber enriched pasta. Journal of Agricultural and Food Chemistry 50(2): 347-356.

Wang, N. Hatcher, D.W. Tyler, R.T. Toews, $R$ and Gawalko, E.J. 2010. Effect of cooking on the composition of beans (Phaseolus vulgaris L.) and chickpeas (Cicer arientinum L.). Food Research International, 43:589-594.

WINA 2016.World instant noodles association, http//instant noodles.org/noodles/report,htm.

Zeinstra, G.G., Koelen, M.A., Kok, F.J., and C. de Graaf 2010. The influence of preparation method on children's liking for vegetables. Food Quality and Preference, 21(8):906-914.

\section{How to cite this article:}

Shere P. D., A. N. Devkatte and Pawar V. N. 2018. Studies on Production of Functional Noodles with Incorporation of Spinach Puree. Int.J.Curr.Microbiol.App.Sci. 7(06): 1618-1628. doi: https://doi.org/10.20546/ijcmas.2018.706.193 